\title{
Primary Healthcare Professionals' Experiences of the Sick Leave Process: A Focus Group Study in Sweden.
}

\author{
Emma Nilsing, Elsy Söderberg, Carina Berterö and Birgitta Öberg
}

\section{Linköping University Post Print}

N.B.: When citing this work, cite the original article.

The original publication is available at www.springerlink.com:

Emma Nilsing, Elsy Söderberg, Carina Berterö and Birgitta Öberg, Primary Healthcare Professionals' Experiences of the Sick Leave Process: A Focus Group Study in Sweden., 2013, Journal of occupational rehabilitation

http://dx.doi.org/10.1007/s10926-013-9418-0

Copyright: Springer Verlag (Germany)

http://www.springerlink.com/?MUD=MP

Postprint available at: Linköping University Electronic Press

http://urn.kb.se/resolve?urn=urn:nbn:se:liu:diva-89836 


\section{Primary healthcare professionals' experiences of the sick leave process: A focus group study in Sweden}

Authors: Emma Nilsing1§, Elsy Söderberg², Carina Berterö3 ${ }^{3}$ Birgitta Öberg1

${ }^{1}$ Division of Physiotherapy, ${ }^{2}$ Division of Community Medicine, ${ }^{3}$ Division of Nursing Science

Department of Medicine and Health Sciences, Linköping University, Linköping, Sweden

$\S$ Corresponding author

E-mail address: emma.nilsing@liu.se 


\section{Abstract}

Purpose: The aim of this study was to explore primary healthcare (PHC) professionals' experiences of the sick leave process.

Methods: This is an explorative study using data from four semi-structured focus group discussions with a purposeful sample of PHC professionals in Östergötland County, Sweden. Content analysis with an inductive approach was used in the analysis.

Results: Four key themes emerged from the analysis; priority to the sick leave process, handling sickness certifications, collaboration within PHC and with other stakeholders, and work ability assessments. Patients' need for sick leave was handled from each professional group's perspective. Collaboration was considered important, but difficult to achieve and all the competencies available at the PHC centre were not used for work ability assessments. There was insufficient knowledge of patients' work demands and contact with an employer was rare, and the strained relationship with the social insurance officers affected the collaboration.

Conclusions: This study highlights the challenges physicians and other PHC professionals face when handling the need for sick leave, especially when encountering patients with symptombased diagnoses, and the influence of non-medical factors. Hindrances to good practice were increased demands, collaboration, and role responsibility. The challenges in the sick leave process concerned both content and consequences related to poor collaboration within PHC and with representatives from various organizations, primarily employers and social insurance officers. Further research on how to develop a professional approach for handling the sick leave process is needed.

Keywords: sick leave, work ability, rehabilitation, return to work, physicians, healthcare professionals, sickness certificates, primary healthcare, Sweden. 


\section{Background}

Long-term sick leave remains high in many Western European countries [1, 2]. In many of these countries, sickness benefits are given to those who cannot work due to disease or injury. In social security systems similar to that in Sweden, sick leave is certified by physicians who determine whether a disease or injury is present, and whether the disease or injury limits the patient's functioning to the extent that the work ability is also reduced in relation to the demands at work. The information is provided in a sickness certificate which the social insurance office uses to make the decision regarding entitlement for sickness benefits [3, 4]. Sickness certification is therefore an important part of physicians' ordinary work tasks [3, 4].

There is limited scientific evidence from studies conducted in several countries showing that physicians, especially those in primary healthcare (PHC) practice, consider sickness certification problematic [5-9, 4, 10], or even as a work environment problem [11, 12]. One of the problems related to sickness certification is the difficulty in handling the dual roles of patient advocate and medical expert for other authorities like social security, where the responsibility to the patient often outweighs that of medical expert [9, 8, 13, 4, 11, 14]. Physicians have reported assessments of functioning, work ability, and the need for sick leave as being problematic [6, 15, 4], especially when the patient describes symptoms that are difficult to diagnose and clinical findings are missing $[9,5,13,16]$. The sickness certification is then based on the patient's description of his or her symptoms and work situation [17-19]. The challenges physicians face in sickness certifications may come from insufficient competence to assess work ability [10, 7, 20] as well as scarce knowledge about workplaces, the labour market, and the social security system $[9,17,15,21]$. The sickness certification tasks also include interactions with other stakeholders, but physicians have reported problems in cooperating with stakeholders within or outside the healthcare system [17, 18, 9, 21, 7]. The stakeholders comprise the healthcare, legal (social insurance office), workplace (employer or employment agency), and personal systems (the patient) [22]. Within the healthcare system, many different healthcare professionals are involved in supporting the sick listed patient, including physicians, psychologists or counsellors, nurses, physiotherapists, and occupational therapists. When there is a need for sick leave the physician together with the patient considers the advantages and the disadvantages of being on sick leave, 
determines the grade (full-time or part-time) and duration of sick leave, and what actions that need to be taken during the sick leave period in terms of investigations, treatments and rehabilitation interventions [3]. Previous research has shown that physicians belief that sickness certifications would benefit of involvement of other healthcare professions $[18,10,8,23]$ and that physiotherapists [24, 23] and occupational therapists [25] feel they have the competence to participate in work ability assessments. The few studies investigating the team members' roles indicate however an ambiguity in the team whether other healthcare professionals are supposed to work with work ability assessments [26].

In several European countries, efforts have been made to improve the quality of work ability assessments in relation to sickness certification [27-29]. Sick leave guidelines are one way to improve the quality of sickness certifications, but awareness and use of guidelines is difficult to achieve as acknowledged in a study from the United Kingdom [20]. In Sweden, sick leave guidelines were implemented in 2008 with the aim of facilitating the management of sick leave cases and providing a structure for cooperation between the healthcare sector and social insurance system, and facilitating communication with patients [27]. The guidelines comprise general principles regarding the management of sick leave and specific recommendations for sick leave, length, and grade according to diagnoses. The general principles include recommendations regarding required documentation in sickness certificates, the assessment of work ability as a tool for intervention, patient participation, early commitment, contact with the workplace, and assessing functioning and work ability related to work demands and possible work modifications [27]. Recent surveys conducted in Sweden showed that a majority of physicians perceive the guidelines as being useful, primarily in communication with patients [30]; however, physicians still experience work ability assessments as being difficult [31]. In the United Kingdom, sharing the sickness certification responsibility is part of the fitness for work initiative, which aims to develop the roles of the key members of the PHC team [28] and the NICE guidance on long-term sick leave provides opportunities for other healthcare professionals to assist in early return to work [32]. Thus far, scientific studies investigating the effect of the use of the guidelines have not yet been published internationally. In order to improve the sick leave process including work ability assessments, better knowledge about how the sick leave process is experienced by the team members is needed as a starting point. In light of the challenges 
physicians face in assessments of functioning, work ability, and need for sick leave, this knowledge is important from a healthcare perspective. The aim of this study was to explore primary healthcare professionals' experiences of the sick leave process.

\section{Methods}

\section{Study design and setting}

This is an explorative study using data from semi-structured focus group discussions with primary healthcare professionals. Focus group discussions were chosen because the interaction facilitates the participants' ability to speak more freely and to express and clarify their beliefs, attitudes, and experiences, and to uncover their more or less unconscious beliefs and understanding, which may be more difficult to achieve with individual interviews. Data quality will be enhanced by these interactions, which weed out extreme or false views [33]. Criteria for effective focus group discussions are summarized as a range of relevant topics, specificity and depth to direct the discussions toward the participants' experiences, and the interaction of different perspectives [34].

The setting for the present study was the PHC in the county council of Östergötland, the fourth largest county council in Sweden, with approximately 431,000 inhabitants and 43 PHC centres in 2011 [35]. The PHC shall, as part of the outpatient care, without restrictions to diseases, age, or patient groups, take responsibility for the population's need for basic medical treatment, care, prevention, and rehabilitation, which do not require medical or technical resources from inpatient care or other specific competencies.

\section{Sampling procedure}

The managers of three PHC centres, one urban and two suburban, and the manager of the corresponding rehabilitation centre to the urban PHC centre in the east part of Östergötland County, Sweden, were contacted. Two of these centres and the rehabilitation centre had signed 
up to implement local guidelines, including a decision basis for sickness certification complementing the physicians' basis for deciding certification of sick leave. A purposeful sampling procedure was conducted. Being a healthcare professional actively involved in the sick leave process was the criteria for inclusion. These healthcare professionals were considered to be those having the richest information since they had experience with the topics being discussed. An invitation that included information about the study was sent to the managers, who distributed the invitation to all healthcare professionals. Those who were involved in the sick leave process and willing to participate contacted the manager. The intention of the sampling for the focus groups was to bring healthcare professionals with dissimilar backgrounds together in heterogeneous groups, which facilitate group discussions [33]. A heterogeneous sampling was therefore conducted with different healthcare professionals, but who were from the same centre. The groups incorporated physicians, physiotherapists, occupational therapists, and counsellors, who also could be a specialist nurse in psychiatrics. Times were set for focus group discussions. The group discussions were carried out at each centre during working hours.

\section{Participants and procedure}

Three healthcare professionals did not participate due to illness $(n=2)$ or vacation $(n=1)$. In total, four focus group discussions were conducted with three to six participants per group, including a total of 18 participants. Before each focus group discussion, the participants completed a questionnaire with queries about age, sex, type of profession, and years as a healthcare professional (Table 1). All focus group discussions were held between February and May 2012 at the respective PHC centres. The first author was the moderator and a second researcher was an observer. The observer took field notes and observed the atmosphere, interactions, and conversation flow. Small-talk preceded and ended all focus group discussions. The interview guide was based on a literature search and developed through individual interviews and discussions with different healthcare professionals, as well as through discussions in the research group and with other researchers in the field. The final version included the entry question "please tell us who you are and which challenges you think PHC faces today". Further questions were: "if I say the word sick leave, what comes in to your mind?”; “describe how you evaluate a 
patient’s need for sick leave?”; "how do you assess the patient's work ability?”; “what is the goal of sick leave?”; "how is the sick leave evaluated?”; "what happens during the sick leave?” and "what do you do when the patient does not return to work as planned?”.

The participants were encouraged to speak freely and from their experience. In order to gain deeper knowledge, the questions were complemented with probes such as "can you tell us more”; “can you explain that”; “what you mean”; loops; and transitions. Each focus group discussion took approximately $1-1.45 \mathrm{~h}$ in free-flowing discussions in a friendly atmosphere. The discussions were digitally recorded and transcribed verbatim by one author (EN), except for one which was transcribed by a transcriptionist and checked for accuracy. The transcripts resulted in total 95 single-spaced pages (Calibri 11 font).

\section{Data analysis}

Data were analysed after all focus group discussions were carried out. In this study, four focus group discussions were carried out, but the fourth discussion did not produce any new information. The data was analysed using the qualitative content analysis described for focus group discussions [33, 34], and an approach for inductive category development. Since the discussions in focus groups depended on both the individuals that made up the group and the dynamics of the group, the analysis strived to balance the interplay between these two units of analysis (i.e. the individual and the group) [34]. The transcripts were read several times by two researchers (EN and ES) to provide a comprehensive picture, and were analysed independently by the two researchers. Consensus discussions were continuously held during the analysis until a shared understanding of all emerging categories was achieved. All quotes connected to the participants' experience with the sick leave process were marked with a highlighter and memos were written in the margin. All quotes were classified into categories and subcategories based on their content, and directed by the aim of the study and the questions in the interview guide. Emphasis was put on quotes that were frequent, but also on those that were gems or showed “cutting-edge thinking”, were specific and detailed, expressed emotion, or that were extensive (i.e. how many different people said something) [33]. During the entire analysis, comparisons were constantly made between the categories and the text as a whole. 
The aim of the analysis was to discover similarities, differences, regularities, contradictions, patterns, and themes in the text [36, 33]. If themes were discovered to cut across the interview questions, these themes then directed the analysis instead of the interview questions. When no new categories appeared from the text, subcategories with similar meaning were brought into main categories, striving to be internally homogenous and externally heterogeneous. The categories were labelled as closely to the words in the original text as possible and summed up the meaning of the category. A summary was written for each of the themes and categories in order to describe what was said. The paper is structured around these themes. Quotes from group discussions capturing the essence of what was said were selected to illustrate the different categories [33]. Finally, the categories and the quotes were discussed in relation to the written data within the entire research group. The selected quotes from the transcripts were translated into English then re-translated into Swedish to secure an identical meaning of the statements.

\section{Ethical considerations}

The study was approved by the Research Ethics Committee of the Faculty of Health Sciences of Linköping University, Sweden. The participants provided informed consent after receiving both written and oral information about the study, including the aspects of voluntary participation, the possibility of withdrawing at any time without explaining why, and that the responses to questions would be handled confidentially and presented anonymously. There was no payment involved.

\section{Results}

Analyses of the focus group discussions revealed that the informants perceived the following four themes of their experiences to be important: 1) priority to the sick leave process, 2) handling sickness certifications, 3) collaboration within PHC and with other stakeholders, and 4) work ability assessments. 


\section{Priority to the sick leave process}

The informants mutually described demanding and stressful daily work with difficulties balancing the growing number of older aged patients as well as increasing external demands, such as investigations and complicated referrals regarding more severe diagnostic groups from inpatient care. These demands required, according to the informants, more specialist than generalist competence, and the physicians especially described challenges in managing these two competencies as well as preserving their competence as general practitioners. Another challenge was the accessibility to healthcare, which is one of the primary goals of the PHC. Some of the informants described people's need for healthcare as inexhaustible, which challenged their ability to provide good healthcare to deserving patients. Additionally, primarily physiotherapists described difficulties in performing individually-tailored interventions and to support the patient in self-care. The informants' perceptions of dealing with these challenges while simultaneously fulfilling the goal of accessibility to healthcare are illustrated in the following quote:

D1: If we are to be that highly accessible so that everyone can get an appointment within one week, many patients should get an appointment on the same day they have fever. And then we take care of all the aging patients, the growing number of elderly// And then, not only do we provide primary care but we also manage specialist cases; then you cannot, then there is no time for rehabilitation interventions as expected.

As a consequence, many physicians and other professionals prioritized patients with acute or severe diagnoses, and not for investigating the need for sickness certificates or concluding rehabilitation processes.

\section{Handling sickness certifications}

The informants' experience with sickness certification included two main problems: Firstly, sick leave was not always interpreted as an intervention having a goal. Secondly, to issue a sickness certificate was considered problematic when physicians found no clinical findings, and instead must rely on the patient's information given during the consultation on subjective symptoms, work tasks, and need for sick leave.

The first problem concerned the view of sick leave as an intervention having a goal, such as prescribing medications, counselling, or physiotherapy. This view was questioned by some 
informants, who instead considered sick leave a period needed for recovery or rehabilitation. They did not make an appointment for a follow-up since they were convinced that the patient would get in touch when he/she cannot return to work as planned. The latter was perceived as time efficient and convenient in most cases, but when a patient asks the PHC to provide for prolonged sick leave on short notice, there may not be sufficient time to perform the required assessments, or another physician may have to re-evaluate the need for sick leave. When the informants were unclear about the patient's need for a sick leave period or suspected a patient was seeking a solution for problems experienced in private life or at work, it was perceived as very difficult to rehabilitate the patient regardless of which interventions were performed or efforts made. The informants' disparate perceptions of the goal and handling of sick leave are illustrated in the following dialogue between the participants in focus group B:

B1: Yes, it [the goal of sick leave] depends on, as you say, it can be your income, and then it is difficult to get through, I mean, to help that person.

B2: It can also be difficult to get anywhere in the rehabilitation if you need sick leave to manage your income; then I don't think you are willing to get any better, so that is an uphill struggle, a major uphill struggle already from the start.

B1: But otherwise, the goal is that they will get well, feel fine, become independent, so it should be

B3: But I don't know if you can say that the sick leave itself has a goal // The sick leave has a cause. I don't know if the sick leave has a goal, although you may not agree with me. The cause for sick leave is a disease which limits the patient's ability to work, so is it really, but I don't know of any goal.

B1: I don't think you see sick leave as an intervention, either. It is rather what you should do during that period.

B2: Sick leave may be seen as a possibility because, if you look at musculoskeletal disorders, then it is possible for the patient to manage their work by preventing recurrences in this disease, injury, or whatever it is about.

B3: It's the same for mental disorders as well.

B4: You can also see sick leave partly as a form of intervention, sometimes it can be, I think that many physicians also use sick leave as part of the treatment and the goal is to return to work ... but not always.

The handling of patients' sickness certification was mutually expressed by the physicians as time consuming and leading to increased work load, as shown in this dialogue:

D1: Yes, but it takes time and you don't have that time. You often have short appointments with patients then you first examine them, give some treatment, document it, and then these sickness certificates. 
D2: Yes, it's additional work.

The second problem concerned handling the need for sick leave when the patient has vague or subjective symptoms such as tiredness, anxiety, or pain. The lack of clinical findings in these patients aggravated the physicians' assessment of the patient's work ability and need for sick leave. Some of the informants expressed that they found it impossible to make an assessment because there was nothing more to assess and certify than the patient's story. The majority of the informants reported insufficient knowledge regarding the demands at the patient's workplace, which furthermore aggravated the assessment of the patient's work ability and need for sick leave. This made the informants feel insecure, and sometimes even mistrust their patients. These patients often had more complex problems and it was difficult to consider the advantage or disadvantage with a period of sick leave as well as to rehabilitate the patients back to work. By contrast, patients with a disease or injury based on clinical findings, e.g. a heart attack or a fracture, were not problematic to certify or recommend sick leave due to the informants' competence and feelings of doing something good for the patient. The problems with lack of clinical findings and sparse knowledge about the patient's workplace are highlighted in the following dialogue between a physician and an occupational therapist:

\footnotetext{
C3: Anxiety (laugh) and a thought that this will take time because it takes time to write a sickness certificate. And the anxiety comes because you don't think they should be sickness certified. That you should motivate and convince them that they should not be sickness certified, that's what's hard. If they have an injury or a disease then there is, of course, no problem. It's those who complain of being tired, having pain somewhere, or do not have the strength who are the hard ones, those with vague symptoms. And you don't really know what they work with or who their colleagues are, and you don't have the time to visit the workplace to see how it really works and how hard it is. It is only guesses from my point of view, you guess all the time, and that does not feel good.

C2: Yes, if you have a fracture, for example, and a physically demanding job, then of course, maybe you should not work these weeks; but it is likewise unclear if somebody comes with numbness saying 'I cannot work', and when you start to unravel it, and it is quite different things, and what is what, and what does it say, and then it is even more difficult with sick leave.
}

The majority of informants described that even on the first encounter with a patient they might have a strong feeling of risk for long-term sick leave. They described that factors other than strictly medical ones were those hindering rehabilitation and returning to work, such as lack of 
motivation among patients, conflicts at workplaces or with authorities, or family problems and lack of social support. Even though the patient may have a less severe disease, the presence of these factors often implied problems, including risk for long-term sick leave. The informants were uniformly confident in their ability to detect patients at risk, but they lacked strategies and tools for identifying and tailoring interventions. In relation to these risk factors, one group primarily discussed the narrow view of disease and work ability applied when sickness benefits are granted in the Swedish National Insurance Act. This narrow view was, according to the informants, in conflict with the complexity of their patients' health problems, and the informants felt confined by the law and regulations of the National Insurance Act and the social insurance officers' strict application of the law.

\section{Collaboration within PHC and with other stakeholders}

Interaction between the different professionals at the PHC centre, inpatient care, occupational health services, and other stakeholders such as social insurance offices and employers was collectively considered to be very important. Overall, the informants perceived a consensus between the physician and the patient on interventions during the sick leave period and an explicit plan for return to work as essential.

\section{Collaboration with other stakeholders}

Collaboration between inpatient care and occupational health services and other stakeholders such as the social insurance office, employer, or employment office was mutually regarded as unclear and scarce, and mainly took place late in the sick leave period.

A2: Many times, I feel that there is a lack of communication. You expect things from others in a way. That's how I feel about sick leave. It is the general practitioner or the social insurance office or the employer, and then it is myself as a person or my colleagues... it's pending somehow, there is uncertainty. 
When multi-stakeholder meetings were held together with the patient, the social insurance officer, and/or the employer, these meetings were considered valuable as they enabled consensus decisions regarding rehabilitation and return to work. But mostly, the informants mutually described that collaboration with other stakeholders was very difficult to achieve. It was troublesome and time consuming to get in touch with stakeholders like the social insurance office and the employer as a first step towards collaboration. All of the informants questioned and sometimes also reported disrespect for decisions and investigations made by the social insurance officers (SIO). They felt that the SIO distrusted the information they provided on the patient's disability, and that they had to write sickness certificates in a certain way to convince the SIO about the patient's impaired work ability and need for sick leave. The following dialogue from focus group D shows this concern:

D3: But that's what I mean. When you hear sick leave, then you get nervous and scared when you understand that it may be a year before this patient will return [to work]. How can I prove this to the social insurance office together with the patient? We can agree with each other at the PHC centre, but when you have a meeting with the social insurance office then I feel worried.

D5: But it also matters which officer the patient has, because if you have an officer who is experienced and able to read between the lines, then it will be just fine. But, if you have a zealous officer then it all goes to blazes.

The communication with the patient was facilitated by the Swedish sick leave guidelines and the SIOs' strict application of regulations. Many physicians described that the patient's ability to evoke empathy and to verbally describe his or her activity limitations, work tasks and demands, and needs in a trustworthy way was important for determining what information the physician would issue in the sickness certificate. Physicians strived to be honest with the patient and the social insurance office, but sometimes these dual roles were conflicting. Depending on the purpose of the sickness certificate, the information regarding symptoms and disabilities might be exaggerated or understated by the physician, as shown in the next quote:

C3: Yes, I do know that the social insurance office wants pretty detailed information in order to entitle sickness benefits, and if you write a bit fuzzy, first of all they will request a complementary (laugh). If you keep writing fuzzy then the patient often does not receive sickness benefits, but it is important to be honest with the patient and tell them that there is a risk that you will not receive benefits. There are some cases like pain where you don't find anything real. They may have pain but you can't find anything. Those are the hard ones. 
Some of the groups discussed factors facilitating return to work. These factors were primarily connected to the patient's workplace such as satisfaction with work tasks, support from coworkers and employers, and early contact with the workplace and part-time sick leave. The informants mutually described their sparse knowledge of the patients' workplace as troublesome; however, contacts with the employer, employment agency, or occupational health service were reported as scarce when discussed at all. The informants collectively expressed increasing demands from employers and the labour market requesting that the patient work fulltime or to be $100 \%$ sick-listed. A few informants described contact with employers as valuable, but also as doubtful since the employer may have a different point of view than the patient. Frustration was collectively felt over waiting periods for investigations or second opinions performed or referred by inpatient care. The informants felt that no one really took full responsibility for assessing work ability, and that the responsibility rests within the PHC system having unrealistic expectations for managing assessments of work ability.

\section{Collaboration within the PHC centre}

The informants primarily described the patients' need for sick leave handled from each healthcare professional group's perspective. The professionals focused on their assessments, interventions, and collaboration within their own profession and competence. Professionals other than physicians were seldom active in sickness certifications, although they often had to discuss and defend the physicians' decisions on sickness certification with their patients. Almost all of these professionals expressed relief that they did not have the authority to certify sick leave. When encountering a patient requesting a sickness certificate, they described different options: treat the patient's clinical problem and refer the patient's request for sick leave to a physician without being involved in the sickness certification task; talk to a physician about the patient's need for a sick leave period; or challenge the patient's expectations of sick leave. Some physicians described being put in a situation characterized by negotiations when a patient requests a sickness certificate. This negotiation may in return involve a referral to a physiotherapist as a counter-performance. One physician and a physiotherapist explained the situation as follows: 
A1: Because it's almost always the patient who initiates the question, you want to proceed to ask why you think you cannot work, what are the obstacles, and is there a possibility to do something else. These are the questions that arise then. And you often do get an immediate answer; no, there is only this work and it's so specific that there are no other alternatives. The boss does not understand me, maybe. So that's a kind of negotiation or discussion with the patient, and then you often end up with a sickness certification. But then you try to come up with something to offer as kind of a counter option, not a counter option, but something like you have to see a physiotherapist or an occupational therapist, or whatever it may be, or counselling. Often counselling, actually, so that you can make some progress.

A4: Yes, at first I normally do, since I cannot decide about that thing, but I normally start by asking them what type of work they do, what the cause could be in a discreet way. And if I feel that it would maybe be beneficial with a short-term sick leave then I refer to the patient's physician or I talk to one of the physicians at the PHC centre. By talking to each other, you will see if the physician will see the patient or if there will be a sick leave just by that contact. And if I feel that sick leave is not appropriate, I try to explain how I think and that it may work anyway if we do it this way. But of course, the patient doesn't always agree.

Even though teams existed, the analysis revealed that the collaboration in the PHC centre regarding sickness certification cases lacked structure and consisted primarily of unscheduled conversations, mainly regarding which interventions should be taken during the sick leave. This type of communication was facilitated by the internal organization of the PHC centre and more easily accomplished at the PHC centre where all the healthcare professionals were gathered. During the discussions, the physicians faced challenges with determining the validity of the medical history of patients with musculoskeletal pain requiring functional assessments, and took initiatives for collaboration between physicians and physiotherapists. Only in one of the focus groups was an active policy for handling the sick leave process mentioned. The policy was, however, not used in their daily work with sickness certification cases.

\section{Work ability assessments}

The informants described different perceptions of work ability assessments. Some of the physicians reported that they mapped the patient's story about their impairments and related these to the demands at work by asking the patient to describe work tasks and demands at work and how the impairments limited their ability to perform the required tasks. This assessment was based on a feeling of trust in the patient and the patient's story. The patient's story constituted the basis for an assessment of work ability given in the certificate. Others were more frustrated and described the assessment as theoretical or a guessing game. Overall, knowledge about the 
patient and earlier sick leave periods influenced the feeling of trust. The following conversation between two physicians illustrates this perception of assessment of work ability:

D2: Assessment of work ability is very arbitrary, it's very arbitrary. If the patient says, "no, it does not", well, then no, then it won't.

D1: Yes, that depends a bit on your view of the patient. If it's someone you've known for ages, who isn't frequently absent or complains a lot, when that person complains then you believe more in him or her. If there is someone who has had much sickness absence for many different reasons, then you are less likely to trust their words.

D2: Humph, no, but if your starting point is that you don't know the patient then the work ability assessment will be based on the patient's story. If they say they cannot work, then they don't have any work ability either.

D1: And then a follow-up question; what do you do at your workplace? Do you lift a lot, do you have to bend? What is it that you cannot do and is there something else at work that you could do? Then you often get the answer "no"

Physiotherapists, occupational therapists, and counsellors often disclaimed their responsibility and were anxious to explain that they do not assess work ability. They were involved mostly when the patient was already sickness certified. Physiotherapists described assessments of functional impairments, and occupational therapists applied a broader perception of work ability; for instance, measuring activities in daily life at the patients' home as an indicator of impaired work ability. The latter professionals were striving for a holistic picture, but they were very vague when explaining what they meant by assessing the patient from a holistic perspective. Work related factors and instruments for assessing work ability were seldom discussed. Interview instruments were described by occupational therapists, but they rarely used them. The following conversation between a counsellor, a physician, and an occupational therapist shows the insecurity towards work ability assessments and the different perceptions of assessment of work ability are stressed:

\section{C1: Well, no, I don't [assess work ability]}

C3: No, it is a guessing game, pure guessing. There are no facts behind it. You try to ask what kind of work tasks they have to form an opinion, then you assess that in percentage. You have to estimate, but a little guessing is in it, though. But, sure, sometimes you can agree upon something that is pretty much like reality, but not always

C2: No, and our team gets these kinds of investigations, but we don't assess work ability. We assess activity and functional ability, so that is not in any degree how well I can return to my work but is instead, in principal, how is daily living? Can I do my daily activities, or do I have routines for the day and can I dress 
myself? Do I manage my household? Then the physiotherapist does an ordinary physiotherapy assessment based on some strength, balance, and functioning. But often when that everyday living doesn't function, then returning to work will not function either, because then there is something somewhere. The answer may not necessarily be sick leave, but work ability; we just don't assess that.

\section{Discussion}

This study identified four major themes related to the informants' experiences with the sick leave process; priority to the sick leave process, handling of sickness certifications, collaboration within the PHC system and with other stakeholders, and work ability assessments. Sickness certification cases were handled from each professional group’s perspective, and the available competence at the PHC centre was not used for work ability assessments. Collaboration was considered important. However, despite lack of knowledge regarding work demands, contact with the employer was rare, and the strained relationship with the SIO affected the collaboration.

\section{Priority to the sick leave process}

The challenges identified in PHC were increasing demands from inpatient care, growing number of older patients, patients having more severe diagnoses, and fulfilling the goal of accessibility to healthcare. As a consequence, the sick leave process was not prioritized. The challenges with increased professional demands and diminished control were previously identified as obstacles for doing an optimal job with sickness certifications and rehabilitation activities, as reported by Edlund in an interview study with physicians [21]; however, we found this to be valid for all healthcare professionals.

\section{Handling sickness certifications}

We found that sickness certification tasks were perceived as extra work, and the view of sick leave as an intervention was questioned. These finding suggest that sick leave may not be handled as an active intervention requiring the same high quality standards as other health care activities, which the Swedish sick leave guidelines recommend [27]. A request for an active participating patient in order to manage sickness certifications was identified, which agrees with the guidelines [27]. While patients own understanding of the need for sick leave guided the physician regarding sickness certification before the guidelines [21], our findings suggest that physicians today use the guidelines to communicate with patients, which is in line with a recently published study [30]. However, we also found that physicians sometimes do not fully trust their 
patients. It appears to be difficult to place the patient in the centre of the sickness certification consultation [9, 37], which may be related to the character of the sickness certification consultation and the conflict in playing the dual roles of patient advocate and medical expert to the social insurance system, where the patient's rights to sickness benefits will be reviewed based on the work ability assessment. There may also be an internal conflict in the advocacy role, as shown in the difficulties deciding whether to meet a patient's request for a sickness certificate or not, primarily when clinical findings are missing. Our findings suggest that the challenges with handling the need for sick leave in PHC are not only faced by physicians, as previously reported [38, 9, 8, 4, 11], but also by other professionals. These professionals' described challenges in defending the physician's decision to not issue a sickness certificate, convincing the patient to stay at work, or arguing with the physician about the patient's need for sick leave. The challenges identified in this study agree in many ways with those from von Knorring and colleagues [8], e.g. regarding the challenges with lack of time, problems in assessing work ability, communicating with the SIO, and the role conflict. In our study, the conflict in role responsibility between the patient advocacy and medical expert for the social security system was found to be valid for different professionals, who primarily considered them to represent the patient. This role conflict has been reported by physicians $[9,11,8]$ and recently also by physiotherapists [24].

The informants described non-medical factors such as lack of motivation among patients, conflicts at the workplace or with authorities, and family problems or lack of social support as risk factors for long-term sick leave. Similar findings were made in a study by Pransky and colleagues [17] where the physicians reported barriers in helping the patient return to work, such as long-term sick leave requests, mental disorders, conflict with the employer, and work dissatisfaction [17]. According to previous research, individuals with older age, history of previous sick leave, worse mental and physical functioning, negative expectation of recovery, lower socio-economic status, and impaired work ability are at increased risk for long-term sick leave. Work-related factors such as high physical demands of the job, lack of job control, manual material handling, and lack of social support in the workplace are also important predictors for longer duration of sick leave [39-42]. The results of our study suggest that PHC professionals feel they have the knowledge to detect patients at risk for long-term sick leave at the first 
encounter. This knowledge was based on previous experiences with patients with complex problems; however, strategies and tools to identify and tailor interventions according to these needs so far have not been implemented.

\section{Collaboration}

We found that patients' need for sick leave was handled from each PHC professional group's perspective and a structure, e.g. policies or guidelines, for handling these cases within the PHC centre was not implemented. Collaboration with other stakeholders was considered important and warranted, but difficult to achieve. Physicians are responsible for documenting work demands in sickness certificates, but our findings indicate that physicians and other healthcare professionals have sparse knowledge regarding work demands, and insufficient prerequisites to contact the employer. This supports earlier studies reporting that direct contact with the employer is rare $[17,21,37,5]$, and that physicians rely on patients' self-reports of working conditions and available work modifications rather than obtaining information from the employer [17]. The limited contact with the employer might have implications for patients' return to work. Better communication could facilitate the healthcare professionals' assessment regarding whether the work demands are suitable to the patient's functioning or not, but would also increase the healthcare professionals' awareness of available work modifications or alternatives, and improve the employer's awareness of the patient's need for specific modifications [43].

The informants in our study described an especially strained relationship with the SIO, and disrespect was shown for decisions and investigations performed by the SIO. It was perceived as difficult to communicate to the SIO when patients have a more complex need for sick leave, since sickness certificates with such information would not be accepted by the SIO because of the increased demands regarding clear descriptions of the patient's work disability and adherence to the time-limits for sick leave length [27]. These findings are in agreement with those from Hussey and colleagues [9], suggesting that the sickness certification practice fails to address complex, chronic, or doubtful cases. We found that some physicians deliberately issued vague certificates, knowing that the sick leave would not be approved by the SIO. This indicates that making assessments in the role as medical expert for the social insurance office is difficult to maintain, which supports previous findings $[9,14]$. The lack of trust and confidence in each 
other affecting the collaboration between the SIO and the healthcare system has been described as a conflict explained by different perspectives on disease and work ability; reductionist versus holistic [44, 26]. The view of what constitutes work disability highlights the discrepancy between the legal and medical perspectives on work ability. There is apparently a conflict between the narrow view of disease and work ability applied in the Swedish National Insurance Act, and with the complexity of patients’ problems causing the work disability.

\section{Work ability assessments}

We found different perceptions of work ability assessments among PHC professionals. The most central aspect of physicians' sickness certification tasks is to determine whether a patient has a disease, and to assess the degree to which this disease reduces the patient's functioning and in relation to work demands and work tasks, the patient's ability to work [3]. Our results support previous findings regarding the problems of assessing work ability, especially when clinical findings are missing $[9,13,16,5]$, but also reveal that the presence of psychological, social, or work-related factors aggravate the assessments. The finding that physicians primarily base their assessments on a feeling of trust in the information given by the patient agrees with earlier research [16, 21, 18]. In line with a previous study [16], we found that the patient's ability to evoke empathy and describe his or her symptoms and working conditions played an important role in obtaining the sickness certification. On the other hand, we also found that there was uncertainty in what the patient expected and a lack of trust in the information given by patients, and the assessment of work ability was described as a guessing game. Earlier research suggested that physicians may not have sufficient competence to assess work ability [7, 20], and scarce knowledge about workplaces, the labour market, and the social security system [9, 15, 17, 21]. Wynne-Jones investigated attitudes among general practitioners [10] and found that physicians reported a lack of training in handling of sickness certifications, particularly in addressing work issues, and that it is within scope for other health professionals to be involved. Von Knorring and colleagues [8] found that physicians experienced problems in not having access to advice and counselling by other healthcare professionals when assessing work ability [8]. Our study indicates that other healthcare professionals have competence to assess different aspects of work ability, but that this competence is not used in sickness certifications or communicated in the PHC. The physiotherapists reported assessing body impairments and activity limitations, and the 
occupational therapists reported assessing activities of daily life; however, neither they nor the counsellors felt that their competence was requested. There are few studies investigating the role of other healthcare professionals in sickness certifications [23, 26], but two previous Swedish interview studies with physiotherapists [24] and occupational therapists [25] confirm our findings regarding available competence to assess work ability, which is not being requested. The informants in our study appeared less confident in their competence to assess work ability than in the two previous studies [24, 25]. The work ability assessment is central for entitlement of sickness benefits in the Swedish social security system, but our findings indicate that the work ability assessment may not be that central in practice. This finding is supported by an interview study with physicians, who did not perceive work ability assessments as a main assignment, but rather something they were forced to handle [18]. Whether sickness certifications would improve with the involvement of other healthcare professionals in work ability assessments needs to be further investigated.

\section{Strengths and limitations}

By covering a relevant range of topics and encouraging the informants' to speak from their experience of the sick leave process, we were able to reach both wide and deep and also to minimize the public voice. The group discussions were lively and the interactions were facilitated by the group composition consisting of different professionals from the same PHC centre. The moderator (EN) had dual roles as both a researcher and clinician (physiotherapist from another county council) and as an insider. Insights can be gained by capitalizing on a shared culture and feelings of collegial trust [45]. The role of the moderator was to facilitate group interactions and conversations among the informants, which outweighs the risk of feelings of being judged. The data was analysed systematically and independently by two researchers (EN, ES) with qualitative content analysis and using an inductive approach [33]. Because one of the researchers was a clinician and the other was a researcher in social medicine, the different theoretical and practical perspectives may have enhanced the understanding of the PHC practice investigated. During the analysis, the entire research group continuously held consensus discussions. The findings were finally discussed with other healthcare professionals, researchers in the field, at seminars, and during the referee process. 
We do not have details of those who chose not to participate and why. The participants were hopefully those most interested in the sick leave process, and therefore were also willing to discuss these topics. The issue of sample size was considered to be reached since the fourth group did not produce new information [36]. The group size from three to six participants could be seen as a study limitation; but, the participants in each group were actively involved in the discussions, and the small group size may have facilitated their ability to speak more freely and reach greater depths [33]. We considered the data to be rich since new aspects not previously published emerged from the analysis. A few participants with higher education or hierarchical position had a tendency to talk more than the others [33]; however, all groups had comparable interactions. The participants were selected from only one county council, which may be considered as a limitation. The main goal of this study was to understand reality, not to explain it, and the reader must decide whether these findings can be transferred to similar contexts [33]. The findings from this study may serve as a starting point for further investigations of how the sick leave process may be developed in primary healthcare.

\section{Conclusions}

This study highlights the challenges physicians and other PHC professionals face when handling the need for sick leave, especially when encountering patients with symptom-based diagnoses and the influence of non-medical factors. Hindrances to good practice were increased demands, collaboration, and role responsibility. The challenges in the sick leave process concern both content and consequences related to poor collaboration within the PHC and with representatives from various organizations, primarily employers and social insurance officers. Further research on how to develop a professional approach for handling the sick leave process is needed. 


\section{Conflict of interest}

The authors declare that they have no competing interests. The study was funded by the County Council in Östergötland, Sweden.

\section{Acknowledgements}

The authors would like to thank all the healthcare professionals who agreed to be interviewed. 


\section{References}

1. Gimeno D, Benavides FG, Benach J, Amick BC, 3rd. Distribution of sickness absence in the European Union countries. Occup Environ Med. 2004;61(10):867-9.

2. Alexanderson K, Norlund A. Swedish Council on Technology Assessment in Health Care (SBU). Chapter 1. Aim, background, key concepts, regulations, and current statistics. Scand J Public Health Suppl. 2004;63:12-30.

3. Wahlstrom R, Alexanderson K. Swedish Council on Technology Assessment in Health Care (SBU). Chapter 11. Physicians' sick-listing practices. Scand J Public Health Suppl. 2004;63:222-55.

4. Wynne-Jones G, Mallen CD, Main CJ, Dunn KM. What do GPs feel about sickness certification? A systematic search and narrative review. Scand J Prim Health Care. 2010;28(2):67-75.

5. Timpka T, Hensing G, Alexanderson K. Dilemmas in sickness certification among Swedish physicians Eur J Public Health. 1995;5:215-9.

6. Lofgren A, Hagberg J, Arrelov B, Ponzer S, Alexanderson K. Frequency and nature of problems associated with sickness certification tasks: A cross-sectional questionnaire study of 5455 physicians. Scand J Prim Health Care. 2007;25(3):178-85.

7. Swartling MS, Alexanderson KA, Wahlstrom RA. Barriers to good sickness certification -- an interview study with Swedish general practitioners. Scand J Public Health. 2008;36(4):408-14.

8. von Knorring M, Sundberg L, Lofgren A, Alexanderson K. Problems in sickness certification of patients: A qualitative study on views of 26 physicians in Sweden. Scand J Prim Health Care. 2008;26(1):22-8.

9. Hussey S, Hoddinott P, Wilson P, Dowell J, Barbour R. Sickness certification system in the United Kingdom: qualitative study of views of general practitioners in Scotland. BMJ. 2004;328(7431):88.

10. Wynne-Jones G, Mallen C, Main C, Dunn K. Sickness certification and the GP: what really happens in practice? Fam Pract. 2009;27(3):344-50.

11. Swartling MS, Hagberg J, Alexanderson K, Wahlstrom RA. Sick-listing as a psychosocial work problem: a survey of 3997 Swedish physicians. J Occup Rehabil. 2007;17(3):398-408.

12. Ljungquist T, Arrelov B, Lindholm C, Wilteus AL, Nilsson GH, Alexanderson K. Physicians who experience sickness certification as a work environmental problem: where do they work and what specific problems do they have? A nationwide survey in Sweden. BMJ Open. 2012;2(2):e000704. doi:10.1136/bmjopen-2011-000704.

13. Larsson C, Sydsjo A, Alexanderson K, Sydsjo G. Obstetricians' attitudes and opinions on sickness absence and benefits during pregnancy. Acta Obstet Gynecol Scand. 2006;85(2):165-70.

14. Swartling M, Peterson S, Wahlstrom R. Views on sick-listing practice among Swedish General Practitioners--a phenomenographic study. BMC Fam Pract. 2007;8:44.

15. Osteras N, Gulbrandsen P, Benth JS, Hofoss D, Brage S. Implementing structured functional assessments in general practice for persons with long-term sick leave: a cluster randomised controlled trial. BMC Fam Pract. 2009;10(1):31. 
16. Nilsen S, Werner EL, Maeland S, Eriksen HR, Magnussen LH. Considerations made by the general practitioner when dealing with sick-listing of patients suffering from subjective and composite health complaints. Scand J Prim Health Care. 2011;29(1):7-12.

17. Pransky G, Katz JN, Benjamin K, Himmelstein J. Improving the physician role in evaluating work ability and managing disability: a survey of primary care practitioners. Disabil Rehabil. 2002;24(16):867-74.

18. Stigmar K, Grahn B, Ekdahl C. Work ability--experiences and perceptions among physicians. Disabil Rehabil. 2010;32(21):1780-9.

19. Lofvander M, Engstrom A. An observer-participant study in primary care of assessments of inability to work in immigrant patients with ongoing sick leave. Scand J Prim Health Care. 2003;21(4):199204.

20. Roope R, Parker G, Turner S. General practitioners' use of sickness certificates. Occup Med (Lond). 2009;59(8):580-5.

21. Edlund C, Dahlgren L. The physician's role in the vocational rehabilitation process. Disabil Rehabil. 2002;24(14):727-33.

22. Loisel P, Durand MJ, Berthelette D, Vezina N, Baril R, Gagnon D et al. Disability Prevention new paradigm for the management of occupational back pain. Dis Manage Health Outcomes. 2001;9(7):351-60.

23. Holdsworth LK, Webster VS, McFadyen AK. Physiotherapists' and general practitioners' views of selfreferral and physiotherapy scope of practice: results from a national trial. Physiotherapy. 2008;94(3):236-43.

24. Stigmar K, Ekdahl C, Grahn B. Work ability: concept and assessment from a physiotherapeutic perspective. An interview study. Physiother Theory Pract. 2012;28(5):344-54.

25. Sturesson M, Edlund C, Fjellman-Wiklund A, Falkdal AH, Bernspang B. Work ability as obscure, complex and unique: Views of Swedish occupational therapists and physicians. Work. 2012. doi:10.3233/WOR-2012-1416.

26. Stahl C, Svensson T, Petersson G, Ekberg K. The work ability divide: holistic and reductionistic approaches in Swedish interdisciplinary rehabilitation teams. J Occup Rehabil. 2009;19(3):264-73.

27. Socialstyrelsen. [National Board of Health and Welfare]. Försäkringsmedicinskt beslutsstöd vägledning för sjukskrivning. [Sick leave guidelines]. (In Swedish). Stockholm2007.

28. Black C. Working for a healthier tomorrow. Norwich: TSO; 2008.

29. OECD. Sickness, Disability and Work: Breaking the Barriers. A Synthesis of Findings across OECD Countries. OECD Publishing; 2010.

30. Skaner Y, Nilsson GH, Arrelov B, Lindholm C, Hinas E, Wilteus AL et al. Use and usefulness of guidelines for sickness certification: results from a national survey of all general practitioners in Sweden. BMJ Open. 2011;1(2):e000303.

31. Bremander AB, Hubertsson J, Petersson IF, Grahn B. Education and benchmarking among physicians may facilitate sick-listing practice. Journal of occupational rehabilitation. 2012;22(1):78-87. 
32. Gabbay M, Taylor L, Sheppard L, Hillage J, Bambra C, Ford F et al. NICE guidance on long-term sickness and incapacity. Br J Gen Pract. 2011;61(584):e118-24.

33. Krueger RA, Casey MA, editors. Focus groups: a practical guide for applied research. Thousands Oaks: SAGE Publications; 2009.

34. Morgan DL, editor. Focus groups as qualitative research Qualitative research methods series. Thousand Oaks: SAGE Publications; 1997.

35. Östergötland Landsting. [Östergötland County]. Årsredovisning 2011. [Annual report 2011]. Cited 2012 September 14. Available from http://www.lio.se

36. Patton MQ. Qualitative research \& evaluation methods. 3rd ed. Thousands Oaks: SAGE Publications; 2002.

37. Coole C, Watson PJ, Drummond A. Work problems due to low back pain: what do GPs do? A questionnaire survey. Fam Pract. 2010;27(1):31-7.

38. Cohen DA, Aylward M, Rollnick S. Inside the fitness for work consultation: a qualitative study. Occup Med (Lond). 2009;59(5):347-52.

39. Dekkers-Sanchez PM, Hoving JL, Sluiter JK, Frings-Dresen MH. Factors associated with long-term sick leave in sick-listed employees: a systematic review. Occup Environ Med. 2008;65(3):153-7.

40. Cornelius LR, van der Klink JJ, Groothoff JW, Brouwer S. Prognostic factors of long term disability due to mental disorders: a systematic review. J Occup Rehabil. 2011;21(2):259-74.

41. Vlasveld MC, van der Feltz-Cornelis CM, Bultmann U, Beekman AT, van Mechelen W, Hoedeman R et al. Predicting return to work in workers with all-cause sickness absence greater than 4 weeks: a prospective cohort study. J Occup Rehabil. 2012;22(1):118-26.

42. Alavinia SM, van den Berg TI, van Duivenbooden C, Elders LA, Burdorf A. Impact of work-related factors, lifestyle, and work ability on sickness absence among Dutch construction workers. Scand J Work, Environ Health. 2009;35(5):325-33.

43. Kosny A, Franche RL, Pole J, Krause N, Cote P, Mustard C. Early healthcare provider communication with patients and their workplace following a lost-time claim for an occupational musculoskeletal injury. J Occup Rehabil. 2006;16(1):27-39.

44. Johansen K, Andersen JS, Mikkelsen S, Lynge E. Decision making and co-operation between stakeholders within the process of sick leave. A case study in a Danish municipality. J Interprof Care. 2011;25(1):59-65.

45. Coar L, Sim J. Interviewing one's peers: methodological issues in a study of health professionals. Scand J Prim Health Care. 2006;24(4):251-6. 
Table 1 Overview of the participants in focus groups A-D (n=4)

\begin{tabular}{|c|c|c|c|c|c|c|}
\hline $\begin{array}{c}\text { Focus } \\
\text { group }\end{array}$ & Total & $\begin{array}{c}\text { Sex, } \\
\mathbf{M} / \mathbf{W}\end{array}$ & $\begin{array}{c}\text { Age, } \\
\text { min-max }\end{array}$ & Physicians & $\begin{array}{c}\text { Other } \\
\text { professionals }\end{array}$ & $\begin{array}{c}\text { Years of } \\
\text { experience, } \\
\text { min-max }\end{array}$ \\
\hline A & 6 & $2 / 4$ & $35-53$ & 1 & 1 PT, I OT, 3 C & $5-32$ \\
\hline B & 4 & $4 / 0$ & $28-60$ & 2 & 1 PT, 1 OT & $1-38$ \\
\hline C & 3 & $1 / 2$ & $38-66$ & 1 & 1 OT, 1 C & $5-20$ \\
\hline D & 5 & $2 / 3$ & $33-63$ & 2 & 1 PT, 1 OT, 1 C & $8-37$ \\
\hline
\end{tabular}

PT, physiotherapist; OT, occupational therapist; C, counsellor or nurse with specialist competence in psychiatrics or cognitive behaviour therapy Years of experience, i.e. years in their profession 
Table 2 Summary of primary healthcare professionals' experiences of handling the sick leave process

\begin{tabular}{|l|l|l|l|}
\hline $\begin{array}{l}\text { Priority to the sick } \\
\text { leave process }\end{array}$ & $\begin{array}{l}\text { Handling sickness } \\
\text { certifications }\end{array}$ & $\begin{array}{l}\text { Collaboration } \\
\text { within PHC and } \\
\text { with other } \\
\text { stakeholders }\end{array}$ & $\begin{array}{l}\text { Work ability } \\
\text { assessment }\end{array}$ \\
\hline $\begin{array}{l}\text { Increasing demands } \\
\text { from patients, } \\
\text { inpatient care, and } \\
\text { the social security } \\
\text { system }\end{array}$ & $\begin{array}{l}\text { The view of sickness } \\
\text { certification as an } \\
\text { intervention is } \\
\text { questioned }\end{array}$ & $\begin{array}{l}\text { Collaboration } \\
\text { considered important } \\
\text { and warranted }\end{array}$ & $\begin{array}{l}\text { Derceptions of work } \\
\text { ability among the } \\
\text { health professionals }\end{array}$ \\
\hline $\begin{array}{l}\text { Accessibility to } \\
\text { healthcare }\end{array}$ & $\begin{array}{l}\text { Non-medical factor } \\
\text { obstacles for } \\
\text { sickness } \\
\text { certification, } \\
\text { rehabilitation, and } \\
\text { return to work }\end{array}$ & $\begin{array}{l}\text { Lack of } \\
\text { collaboration and } \\
\text { trust in other } \\
\text { stakeholders }\end{array}$ & $\begin{array}{l}\text { Assessment based } \\
\text { on patient's story } \\
\text { and trust in the } \\
\text { patient when clinical } \\
\text { findings are lacking }\end{array}$ \\
\hline $\begin{array}{l}\text { Sick leave process } \\
\text { not prioritized }\end{array}$ & $\begin{array}{l}\text { Lack of information } \\
\text { and knowledge on } \\
\text { work demands }\end{array}$ & $\begin{array}{l}\text { Lack of structure for } \\
\text { handling sickness } \\
\text { certifications within } \\
\text { PHC }\end{array}$ & $\begin{array}{l}\text { Available team } \\
\text { competence is not } \\
\text { used nor } \\
\text { communicated in } \\
\text { PHC or with others }\end{array}$ \\
\hline $\begin{array}{l}\text { sickness } \\
\text { handled from each } \\
\text { professional groups' } \\
\text { perspective }\end{array}$ & $\begin{array}{l}\text { in work ability } \\
\text { assessments }\end{array}$ \\
\hline
\end{tabular}

